\title{
Hematologic Presentations of COVID-19 Can be Misinterpreted as Acute Myeloid Leukemia
}

\author{
Hedieh Moradi Tabriz, Elham Nazar, Fatemeh Jazayeri, Arezoo Eftekhar Javadi
}

Department of Pathology, Sina Hospital, Tehran University of Medical Siences, Tehran, Iran.

\begin{abstract}
Introduction: COVID-19 infection prompts inflammatory responses and acute lung injury in human beings. Complete blood count with differential is essential investigative tool in its managing. However, very few studies revealed the variations of blood cell morphology in this disease. Case report: We reported a 39-years- old female patient complained of respiratory distress one week prior to hospitalization. The patient suffered from cough, fever, and molecular test was reported positive for COVID-19 infection. Laboratory data revealed severe permanent leukopenia and peripheral blood smear examination showed blastoid cells after remission of respiratory signs. Patient underwent bone marrow biopsy for rule out acute myeloid leukemia. But, on bone marrow sample, only viral cytopathic effects were seen. COVID-19 virus stimulates inflammatory cells to produces various inflammatory cytokines and as a result, viral cytopathic effects on white blood cells is seen. Conclusion: We have described how the characteristic peripheral blood findings of COVID-19 infection can be misinterpret as acute myeloid leukemia.
\end{abstract}

Keywords: COVID-19- hematology- leukemia

\section{Introduction}

Severe acute respiratory syndrome coronavirus 2 (SARS-CoV-2) caused an epidemic of coronavirus disease 2019 (COVID-19). First known in December 2019, it was confirmed a pandemic by the World Health Organization (WHO) on 11 March 2020 as it has rapidly extent over the world [1]. The standard test for COVID-19 presents the reverse transcriptase polymerase chain reaction (RT-PCR) to recognize viral RNA from clinical specimens [2]. COVID-19 is a rapid spreading pandemic with high mortality rate. Assessable hematologic deviations have been distinct in the first COVID-19 patient studies [3]. The hematopoietic system actions a thoughtful character in the notable hyperinflammation, mainly in severely ill patients [4]. Complete blood count (CBC) is a routine test throughout preliminary biological assessment of patients. CBC analyzers such as SYSMEX ${ }^{\circledR}$ (Sysmex Corporation, Kobe, Japan), make available a white blood cell (WBC) with differential count which exhibiting a sorting of WBCs founded on their morphology and their intracellular components. But, the abnormal leukocyte result is rechecked by peripheral blood smear (PBS) examination for reassessment. Herein, we report a COVID-19 positive patient with severe permanent leukopenia on CBC and blastoid cells on PBS who underwent bone marrow biopsy for rule out acute leukemia as first diagnosis.

\section{Case report}

A 39-year-old woman with no known medical history presented to the emergency department in Sina hospital affiliated with Tehran University of Medical Sciences with a 1-week history of fevers, chills, worsening shortness of breath, headache, and malaise. Upon entrance to the hospital, her vital signs included a temperature of $38^{\circ} \mathrm{C}$, heart rate of 100 beats $/ \mathrm{min}$, respiratory rate of 28 breaths $/ \mathrm{min}$, and oxygen saturation of $90 \%$ on room air. She needed oxygen at $6 \mathrm{~L} / \mathrm{min}$ via a nasal cannula when she was in the emergency department. The first chest x-ray revealed perihilar opacification. She had positive RT-PCR test for COVID-19 and was consequently admitted to the COVID-19 unit for controlling of acute hypoxemic respiratory failure and COVID-19. Laboratory data documented before this encounter included hemoglobin of

\section{Corresponding Author:}

Dr. Elham Nazar

Assistant Professor of Pathology, Tehran University of Medical Sciences, Tehran, Iran.

Email: elhamnazar@yahoo.com 
$10.2 \mathrm{~g} / \mathrm{dL}$, red blood cells of $3.8 \times 106 / \mu \mathrm{L}$, platelet of $163 \times 10^{3} / \mu \mathrm{L}, \mathrm{C}$-reactive protein of $36.8 \mathrm{mg} / \mathrm{L}$, prothrombin time of 12.2 , and a partial prothrombin time of 33.8 . The patient's leukocyte $\left(1.5 \times 10^{3} / \mu \mathrm{L}\right.$ with differential count: $84 \%$ neutrophils and $16 \%$ lymphocytes) persistent decreased with immature and blastoid cells on PBS after remission of respiratory symptoms that was requested hematology consultation for her. Because, the patient had persistent leukopenia with suspicious immature and blastoid cells on PBS, she underwent bone marrow biopsy (BMB) and aspiration. Bone marrow aspiration showed shift to left in myeloid series with presentation of extensive immature myeloid series and had about 30\% atypical cells which were suspicious to blast (Figure 1). First, we considered atypical cells were blast and acute myeloid leukemia was main diagnosis. So, immunohistochemistry staining on bone marrow biopsy was done. But, CD34, C-Kit, and terminal deoxynucleotidyl transferase (TDT) were unremarkable (Figure 2). Slides sent to expert hematologic center (Shariati hospital) for rule out leukemia. So, according to patient's history, IHC staining, and result of consultation, viral hematologic effect was established. Base on the diagnosis, the patient received no chemotherapy. After 6 months of follow-up examinations, leukocyte count increased gradually and was $8.1 \times 10^{3} / \mu \mathrm{L}$.

\section{Discussion}

COVID-19 is a disease initiated by SARS-CoV-2, which mostly causes pulmonary inflammatory lesions, and can also make damage and related symptoms of intestinal tract, liver and the nervous system. The virus spread through droplets and contact. The main clinical presentations are fever, fatigue, dry cough, dyspnea, etc. In their recent publication, Mina and colleagues introduced some of the usual hematological exhibitions of the COVID-19 viral pandemic [5]. Laboratory tests discovered that white blood cells were normal or decreased

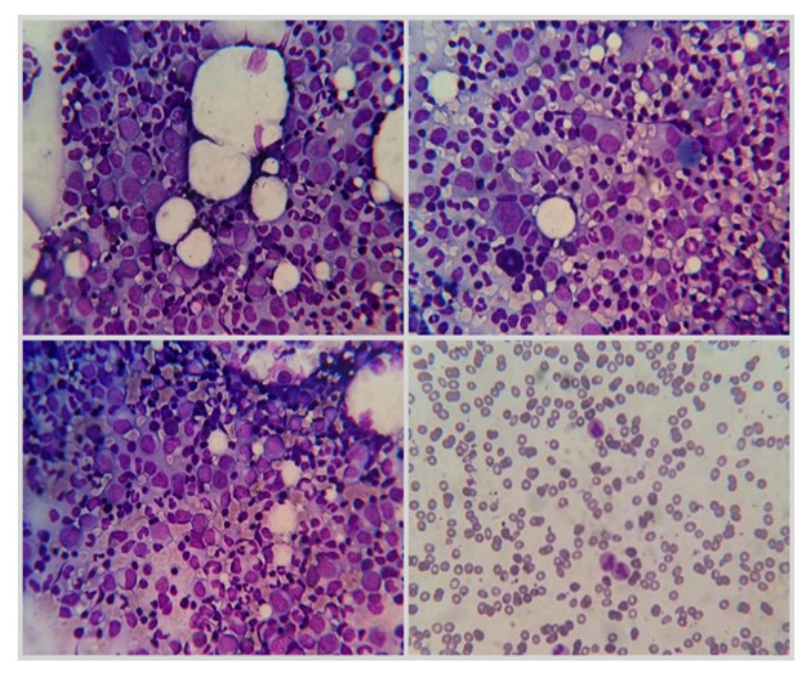

Figure 1. Bone Marrow Aspiration and Peripheral Blood Smear (right lower) Examination Showed Immature Myeloid Cells and Blastoid Cells (Wright\&Giemsa stain, $\mathrm{x} 400)$.

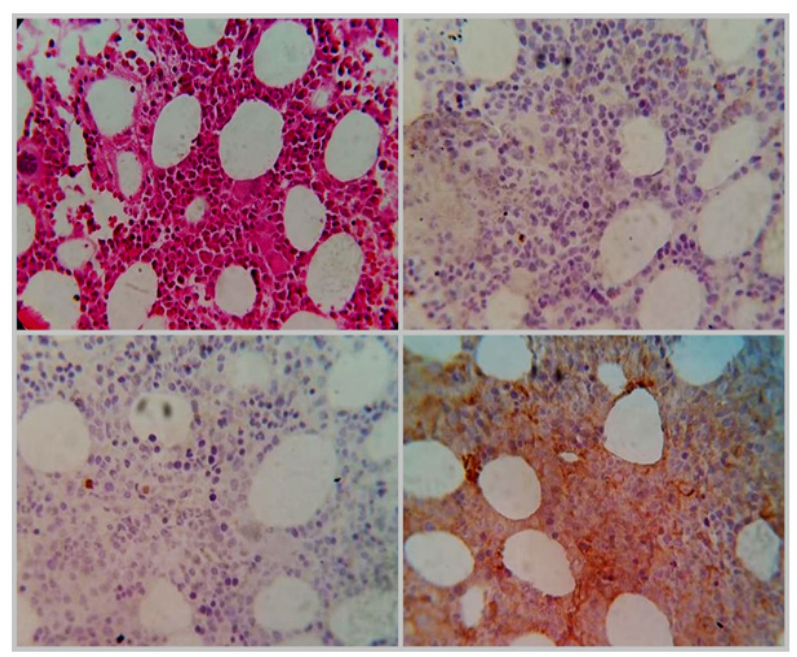

Figure 2. Bone Marrow Biopsy Showed Immature Myeloid Series and Immunohistochemistry Staining Revealed CD34 Positive in 2-3\% Blasts (left upper), TDT Positive in 1\% Blasts (right lower) and C-Kit had Nonspecific Staining (left lower).

and lymphocytes decreased [6]. Like most viruses that influence hematopoiesis and the immune system through progressive stages, COVID-19 enhances release of immature blood cells from bone marrow by inflammatory mechanisms and impress the myelopoiesis system [7]. Patients with COVID-19 have abnormal peripheral blood routine examination results [8]. This is similar to our patient who had immature and blastoid cells on PBS. Leukocyte and neutrophil counts were lower in young patients with COVID-19. Lymphopenia and reactive lymphocytosis, dysplastic changes of granulocytes, and platelets, even though not specific and diagnostic, could be prominent [9] which in our reported case, firstly, leukopenia was seen in laboratory data. Schapkaitz E, et al. study showed on PBS examination, atypical lymphocytes, which are well demarcated in the contextual of viral infections, was discovered in $57.8 \%$ patients. Other common morphological discoveries contained; dysplastic neutrophils and a myeloid left shift [10] which in our case, blastoid cells were dysplastic immature neutrophils series and established by BMB and IHC study. By noticing blood smears colored by Wright-Giemsa stain, we distinguished the characteristics of a neutrophil granulocyte with dysmorphic morphology marked by hypogranular cytoplasm and hyposegmented nucleus due to the upregulation of proinflammatory cytokines in patients with COVID-19 infection were realized [4]. Inhibitory effects of cytokines from virus-involved cells on hematopoiesis might also be responsible for dysplastic changes in myeloid series [11]. Awareness of these patterns of morphologic changes in peripheral blood, if confirmed with greater studies, may aid physicians in diagnose COVID-19 in the lack of a negative RT-PCR test. In addition, some authors have formerly recommended an association among morphological changes in CBC and disease development or outcome [12]. Considering these morphologic variations and hematologic parameters 
by sequential PBS and CBC can help in the diagnosis of COVID-19 and accurate management of COVID-19 patients.

In conclusion, observation of blood cells is able to be a simple alternative tool for the first triage and initial identification of the infection. CBC with PBS can identify the impression of the virus on the blood, reflecting early inflammatory signs. Dysplastic cells due to viral effect should be considered.

\section{References}

1. Zhang D, Guo R, Lei L, Liu H, Wang Y, Wang Y, Qian H, Dai T, Zhang T, Lai Y, Wang J, Liu Z, Chen T, He A, O'Dwyer M, Hu J. Frontline Science: COVID-19 infection induces readily detectable morphologic and inflammation-related phenotypic changes in peripheral blood monocytes. Journal of Leukocyte Biology. 2020 Oct 11;109(1):13-22. https:// doi.org/10.1002/jlb.4hi0720-470r

2. Osman J, Lambert J, Templé M, Devaux F, Favre R, Flaujac C, Bridoux D, Marque-Juillet S, Bruneel F, Mignon F, Diaz-Flores E, Hentgen V, Greder-Belan A, Azarian R, Koukabi M, Rousselot P, Raggueneau V, Manéglier B. Rapid screening of COVID-19 patients using white blood cell scattergrams, a study on 381 patients. British Journal of Haematology. 202007 05;190(5):718-722. https://doi. org/10.1111/bjh. 16943

3. Zini G, Bellesi S, Ramundo F, d'Onofrio G. Morphological anomalies of circulating blood cells in COVID -19 . American Journal of Hematology. 202004 22;95(7):870872. https://doi.org/10.1002/ajh.25824

4. Lüke F, Orsó E, Kirsten J, Poeck H, Grube M, Wolff D, Burkhardt R, Lunz D, Lubnow M, Schmidt B, Hitzenbichler F, Hanses F, Salzberger B, Evert M, Herr W, Brochhausen C, Pukrop T, Reichle A, Heudobler D. Coronavirus disease 2019 induces multi-lineage, morphologic changes in peripheral blood cells. eJHaem. 202006 29;1(1):376-383. https://doi.org/10.1002/jha2.44

5. Murphy P, Glavey S, Quinn J. Anemia and red blood cell abnormalities in COVID-19. Leukemia \& Lymphoma. 202101 22;62(6):1539-1539. https://doi.org/10.1080/104 28194.2020.1869967

6. Yin X, Dong L, Zhang Y, Bian W, Li H. A mild type of childhood Covid-19 - A case report. Radiology of Infectious Diseases. 2020 06;7(2):78-80. https://doi.org/10.1016/j. jrid.2020.03.004

7. Ahnach M, Ousti F, Nejjari S, Houssaini MS, Dini N. Peripheral Blood Smear Findings in COVID-19. Turkish Journal of Hematology. 2020 Nov 19;37(4):301-302. https:// doi.org/10.4274/tjh.galenos.2020.2020.0262

8. Sun S, Cai X, Wang H, He G, Lin Y, Lu B, Chen C, Pan Y, Hu $\mathrm{X}$. Abnormalities of peripheral blood system in patients with COVID-19 in Wenzhou, China. Clinica Chimica Acta. 2020 08;507:174-180. https://doi.org/10.1016/j.cca.2020.04.024

9. Yarali N, Akcabelen YM, Unal Y, Parlakay AN. Hematological parameters and peripheral blood morphologic abnormalities in children with COVID-19. Pediatric Blood \& Cancer. 2020 08 06;68(2). https://doi.org/10.1002/pbc.28596

10. Schapkaitz E, De Jager T, Levy B. The characteristic peripheral blood morphological features of hospitalized patients infected with COVID-19. International Journal of Laboratory Hematology. 2020 Dec 03;43(3). https://doi. org/10.1111/ijlh.13417

11. Akçabelen YM, Gürlek Gökçebay D, Yaralı N. Dysplastic Changes of Peripheral Blood Cells in COVID-19 Infection.
Turkish Journal of Hematology. 202102 25;38(1):72-73. https://doi.org/10.4274/tjh.galenos.2020.2020.0342

12. Kaur G, Sandeep F, Olayinka O, Gupta G. Morphologic Changes in Circulating Blood Cells of COVID-19 Patients. Cureus. 202102 18;. https://doi.org/10.7759/cureus.13416

This work is licensed under a Creative Commons AttributionNon Commercial 4.0 International License. 